Article

\title{
Effect of Various Defects on 4H-SiC Schottky Diode Performance and Its Relation to Epitaxial Growth Conditions
}

\author{
Jinlan Li ${ }^{1,2}$, Chenxu Meng ${ }^{2}$, Le Yu ${ }^{2}$, Yun Li ${ }^{3}$, Feng Yan ${ }^{2}$, Ping Han ${ }^{2, *}$ and Xiaoli $\mathrm{Ji}^{2, *}$ \\ 1 College of Information Engineering, Yangzhou University, Yangzhou 225009, China; 007328@yzu.edu.cn \\ 2 College of Electronic Science and Engineering, Nanjing University, Nanjing 210093, China; \\ mg1823040@smail.nju.edu.cn (C.M.); yule@nju.edu.cn (L.Y.); fyan@nju.edu.cn (F.Y.) \\ 3 Science and Technology on Monolithic Integrated Circuits and Modules Laboratory, Electronic Devices \\ Institute, Nanjing 210016, China; yuefei_2@126.com \\ * Correspondence: hanping@nju.edu.cn (P.H.); xji@nju.edu.cn (X.J.); \\ Tel.: +86-025-83685327 (P.H.); +86-025-89683965 (X.J.)
}

Received: 29 May 2020; Accepted: 22 June 2020; Published: 24 June 2020

\begin{abstract}
In this paper, the chemical vapor deposition (CVD) processing for $4 \mathrm{H}-\mathrm{SiC}$ epilayer is investigated with particular emphasis on the defects and the noise properties. It is experimentally found that the process parameters of $\mathrm{C} / \mathrm{Si}$ ratio strongly affect the surface roughness of epilayers and the density of triangular defects (TDs), while no direct correlation between the C/Si ratio and the deep level defect $Z_{1 / 2}$ could be confirmed. By adjusting the $C / S i$ ratio, a decrease of several orders of magnitudes in the noise level for the $4 \mathrm{H}-\mathrm{SiC}$ Schottky barrier diodes (SBDs) could be achieved attributing to the improved epilayer quality with low TD density and low surface roughness. The work should provide a helpful clue for further improving the device performance of both the $4 \mathrm{H}-\mathrm{SiC}$ SBDs and the Schottky barrier ultraviolet photodetectors fabricated on commercial $4 \mathrm{H}-\mathrm{SiC}$ wafers.
\end{abstract}

Keywords: Ni/4H-SiC Schottky barrier diodes (SBDs); C/Si ratios; 1/f noise

\section{Introduction}

As an excellent wide bandgap semiconductor material, $4 \mathrm{H}-\mathrm{SiC}$ has attracted continuous attention in the last several decades. Due to its wide bandgap, high thermal conductivity, high saturated electron drift velocity and high physical and chemical stability, $4 \mathrm{H}-\mathrm{SiC}$ is an ideal material for high-performance ultraviolet (UV) photodetectors available in high-temperature environments, as well as power devices for high-temperature and high-frequency applications [1-6]. The device performance of both the photodetectors and the power devices greatly depends on the epitaxial quality of commercial $4 \mathrm{H}-\mathrm{SiC}$ wafers, which has been significantly improved in recent years. However, due to substrate material imperfection and epitaxial growth immaturity, there are still various defects in the large-size $4 \mathrm{H}-\mathrm{SiC}$ epilayers, such as morphological defects (micropipes, downfalls, particles, triangular defects (TDs), carrots, etc.), crystallographic defects (stacking faults, threading dislocations, etc.) and deep level defects, etc. [7-15], which will inevitably have a serious impact on the performance of $4 \mathrm{H}-\mathrm{SiC}$ power devices and ultraviolet photodetectors. Among the morphological defects, micropipes have serious impact on the device performance but are preventable, since the substrates with micropipe density less than $0.1 \mathrm{~cm}^{-2}$ are commercially available [16-18]. In our previous paper, we reported the density of other morphological defects in a 4-inch $4 \mathrm{H}-\mathrm{SiC}$ epitaxial wafer, as well as their probability of causing Schottky diode power device failure [19]. The average morphological defect (including TDs, downfalls, particles, carrots) density in the 4 -inch $4 \mathrm{H}-\mathrm{SiC}$ epitaxial layers is $1.25 \mathrm{~cm}^{-2}$, in which the TDs, the downfalls, the particles, and the carrots account for approximately $60 \%, 2 \%, 31 \%$ and $7 \%$, 
respectively. In addition, the probability of causing device failure is $100 \%$ for TDs and downfalls, while the probability of degrading the reverse breakdown voltage of the device is $2 \%$ and $30 \%$ for particles and carrots, respectively. Therefore, among all these morphological defects, the TDs should attract enough attention as the critical device killer. Meanwhile, the deep level defect $Z_{1 / 2}$ center (located at $0.6 \sim 0.7 \mathrm{eV}$ below the conduction band of $4 \mathrm{H}-\mathrm{SiC}$ ) is now considered to be the main life killer of n-type $4 \mathrm{H}-\mathrm{SiC}$ devices. The concentration of the $\mathrm{Z}_{1 / 2}$ is $(0.1-4) \times 10^{13} \mathrm{~cm}^{-3}$ for the commercially available $4 \mathrm{H}-\mathrm{SiC}$ material, which seriously affects the performance of bipolar devices and photodetectors due to the existence of deep level traps [20]. Thus, the TDs and the $Z_{1 / 2}$ defects which widely exist in commercially available $4 \mathrm{H}-\mathrm{SiC}$ epilayers are usually considered as two significant factors that hinder the device performance. The structures of TDs are related to the presence of foreign particle inclusion at the epi-substrate interface, resulting in an increase of leakage current and the reduction of breakdown voltage in the $\mathrm{SiC}$ power devices [21]. The $\mathrm{Z}_{1 / 2}$ defect at $\mathrm{E}_{\mathrm{c}}-0.6 \mathrm{eV}$ originates from carbon vacancies, which may affect the barrier height and leakage current of SiC Schottky barrier diodes (SBDs) [22]. On the other hand, all these defects may increase the recombination of electron-hole pairs and enhance the surface recombination in the Schottky barrier UV photodetectors, leading to a lower responsivity of the device [23,24]. A large number of studies have shown that the formation of these defects is closely associated with growth temperature, $\mathrm{C} / \mathrm{Si}$ ratio, thermal oxidation, carbon ion implantation, thermal annealing, in-situ pre-growth etch and cutting angle of SiC substrate, etc. [25-30].

Therefore, the optimization of growth conditions is critical to the reduction of defects and the improvement of the device performance. Miyazawa reported that the reduction of the $Z_{1 / 2}$ defect concentration is achieved mainly through thermal oxidation/thermal annealing or $\mathrm{C}^{+}$-implantation/thermal annealing, unfortunately, new traps are introduced by these two methods [31]. Yazdanfar pointed out that TD density can be effectively reduced by in-situ pre-growth etch before growth at lower C/Si ratio and growth temperature [32]. However, these methods are very complicated and impractical for industrial processes. In practicality, the variations of growth conditions influence multiple defects in the $4 \mathrm{H}-\mathrm{SiC}$ epilayers, and consequently determine the device performance in an intricate way. It is necessary to survey how these parameters (e.g., C/Si ratio, growth rate and doping density) affect TDs and $\mathrm{Z}_{1 / 2}$ defects, which are the most commonly exsiting defects in the commercial $4 \mathrm{H}-\mathrm{SiC}$ wafers. Meanwhile, the key issue of process parameters optimization is to seek out the critical factors affecting device performance; therefore, it is also important to establish a direct link between the growth parameters and the device performance. By analyzing the results of the electrical parameters of the device performance, not only can the most important defect information affecting the performance be identified, but it can also provide effective suggestions for further optimization of the growth parameters.

In this paper, we investigated the influence of different chemical vapor deposition (CVD) growth conditions on the defect density of $4 \mathrm{H}-\mathrm{SiC}$ epilayers and the electrical properties of $\mathrm{Ni} / 4 \mathrm{H}-\mathrm{SiC}$ SBDs, with particular attention to the TDs and the $Z_{1 / 2}$ defects. The integration of scanning electron microscopy (SEM), atomic force microscopy (AFM), micro-photoluminescence (PL), and micro-Raman was used to study the mechanism of defect evolution in 4-inch $4 \mathrm{H}-\mathrm{SiC}$ epilayers. The combination of reverse leakage current testing, noise measurement, and the deep level transient spectrum testing (DLTS) was used to reveal the root cause of the growth conditions impacting on device performance.

\section{Materials and Methods}

$4 \mathrm{H}-\mathrm{SiC}$ epilayers with different $\mathrm{C} / \mathrm{Si}$ ratios $(\mathrm{C} / \mathrm{Si}=0.9,1$ or 1.1$)$ were homoepitaxially grown on commercially available $4 \mathrm{H}-\mathrm{SiC}$ substrates in a $\mathrm{SiH}_{4}-\mathrm{C}_{3} \mathrm{H}_{8}-\mathrm{H}_{2}$ chemical vapor deposition (CVD) system (AIXTRON VP2400, AIXTRON, Herzogenrath, Germany). In this study, all substrates were commercial chemo-mechanically polished micropipe-free 4 -inch $4 \mathrm{H}-\mathrm{SiC}$. The substrate is highly doped with nitrogen and cut off at $8^{\circ}$ towards [1120] direction. Here, $\mathrm{SiH}_{4}, \mathrm{C}_{3} \mathrm{H}_{8}$ and $\mathrm{HCl}$ were used as source gases while $\mathrm{H}_{2}$ was selected for dilution and carrier gas. The $\mathrm{C} / \mathrm{Si}$ ratio was varied from 0.9 to 1.1 by changing the $\mathrm{C}_{3} \mathrm{H}_{8}$ flow rate at a fixed $\mathrm{SiH}_{4}$ flow rate. The typical epitaxial growth rates were fixed at $60 \mu \mathrm{m} / \mathrm{h}$, and the epitaxial temperature and growth pressure were controlled within 
1550 1600 ${ }^{\circ} \mathrm{C}$ and 50 150 mbar, respectively. Nitrogen gas was used as an n-type dopant, and the typical doping concentration was $1 \times 10^{15} \mathrm{~cm}^{-3}$. Additional 4-inch $4 \mathrm{H}$-SiC epilayers with different growth rate $(v=30 \mu \mathrm{m} / \mathrm{h}$ and $60 \mu \mathrm{m} / \mathrm{h})$ and doping concentration $\left(N_{d}=4 \times 10^{15} \mathrm{~cm}^{-3}, 7.5 \times 10^{15} \mathrm{~cm}^{-3}\right.$ and $1 \times 10^{16} \mathrm{~cm}^{-3}$ ) were also prepared for exploring the dependence of the process parameters on deep defect density, respectively. All the samples (\#1 \#7) have the same thickness of $12 \mu \mathrm{m}$, with different growth parameters summarized in Table 1. After the homoepitaxial growth in CVD system, a $100 \mathrm{~nm}$ $\mathrm{Ni}$ Ohmic contact was formed by annealing in nitrogen at $1000{ }^{\circ} \mathrm{C}$ for $5 \mathrm{~min}$ in the back sides of the device, and a $75 \mathrm{~nm} \mathrm{Ni}$ Schottky contact layer was sputtered with an active area of $1 \mathrm{~mm}^{2}$ in the front sides of the device.

Table 1. The samples of the 4-inch $4 \mathrm{H}-\mathrm{SiC}$ epilayers with different chemical vapor deposition (CVD) growth parameters.

\begin{tabular}{cccccccc}
\hline Samples \# & \#1 & \#2 & \#3 & \#4 & \#5 & \#6 & \#7 \\
\hline C/Si & 0.9 & 1 & 1.1 & 0.8 & 0.8 & 0.8 & 0.8 \\
Growth rate $(\mu \mathrm{m} / \mathrm{h})$ & 60 & 60 & 60 & 60 & 60 & 60 & 30 \\
Doping density $\left(10^{15} \mathrm{~cm}^{-3}\right)$ & 1 & 1 & 1 & 4 & 7.5 & 10 & 7.5 \\
\hline
\end{tabular}

The room temperature micro-PL and micro-Raman spectroscopy measurement were performed on the samples excited by a $325 \mathrm{~nm}$ He-Cd laser, where the laser beam was focused to a spot of $10 \mu \mathrm{m}$ diameter using a sapphire objective lens. Moreover, the atomic force microscopy (AFM) (WET-SPM-model, SPM-9600, Shimadzu Corp., Kyoto, Japan) imaging with a metalized cantilever was carried out for characterizing the surface roughness of wafers. The C- $V$ characteristic measurements (Keithley 4200, Keithley, Cleveland, OH, USA) were conducted at a frequency of $1 \mathrm{MHz}$ to determine the effective doping density of devices based on $1 / C^{2}$ vs. $V$ plots. The noise spectrum was tested to study device noise performance. Deep level characterization of the $4 \mathrm{H}-\mathrm{SiC}$ SBDs were carried out using DLS-83D Deep Level Transient Spectroscopy test system (Semilab, Budapest, Hungary). Temperature ranging from $77 \mathrm{~K}$ to $550 \mathrm{~K}$ was selected by a ACP-4000 temperature controller at a heating rate of $0.1 \mathrm{~K} / \mathrm{s}$.

\section{Results and Discussion}

Figure 1a shows the room temperature micro-PL spectra corresponding to the A and B positions in the illustration for the $4 \mathrm{H}-\mathrm{SiC}$ epilayer grown with $\mathrm{C} / \mathrm{Si}=1.1$. The inset $\mathrm{SEM}$ image at position $\mathrm{A}$ exhibits the crystal structure region of the $4 \mathrm{H}-\mathrm{SiC}$ epilayer without TDs. The strongest peak of 391 $\mathrm{nm}$ corresponding to $3.17 \mathrm{eV}$ is attributed to the typical band edge emission of $4 \mathrm{H}-\mathrm{SiC}$ [33]. However, at the apex of the TDs (position B), the $4 \mathrm{H}-\mathrm{SiC}$ band edge emission intensity at $391 \mathrm{~nm}$ was significantly reduced. Furthermore, an additional small emission peak appeared at $423 \mathrm{~nm}$ corresponding to $2.93 \mathrm{eV}$, which is consistent with the emission wavelength of the stacking fault in the $4 \mathrm{H}-\mathrm{SiC}$ epilayer. This stacking fault is determined by the different stacking order, which is defined as a single Shockley SF (1SSF) using the Zhdanov notation [34,35]. Figure 1b shows typical micro-Raman spectra of $4 \mathrm{H}-\mathrm{SiC}$ at points A and B. The results show two FTO modes at $776 \mathrm{~cm}^{-1}$ and $796 \mathrm{~cm}^{-1}$, and an FLO mode at $964 \mathrm{~cm}^{-1}$, which is consistent with the typical Raman spectra of $4 \mathrm{H}-\mathrm{SiC}$ [36]. However, for the TD region (point B), the intensity of the Raman peak at $796 \mathrm{~cm}^{-1}$ is gradually increased. Since the $3 \mathrm{C}-\mathrm{SiC}$ also has a TO peak at $796 \mathrm{~cm}^{-1}$, the presence of the $3 \mathrm{C}-\mathrm{SiC}$ polytype could be inferred. The ratio of the two peaks can be taken as a measure of the presence of the 3C-SiC polytype [37]. Therefore, we can confirm that stacking faults and the $3 \mathrm{C}-\mathrm{SiC}$ are the reasons of nucleation at the triangle defect vertex. Figure 2 shows the dependence of TD density on the C/Si ratios for $4 \mathrm{H}-\mathrm{SiC}$ epilayers. The wafers (\#1 \#3) were inspected using optical microscopy to evaluate the density of TDs. The results show that the density of TDs is reduced from $1.3 \mathrm{~cm}^{-2}$ to $0.13 \mathrm{~cm}^{-2}$ with the C/Si ratio decreasing from 1.1 to 0.9 . Kojima et al. have reported that the origin of the TDs is attributed to step-bunching caused by the interrupted step-flow growth [38]. In the carbon-rich growth environment $(\mathrm{C} / \mathrm{Si}=1.1)$, the surface free energy of the crystal surface is higher than that under silicon-rich conditions, so it is necessary 
to reduce the surface free energy by the formation of step-bunching [39]. Thus, there is a higher probability of two-dimensional nucleation due to the suppression of the step-flow growth at high C/Si ratios. Consequently, a relatively low $\mathrm{C} / \mathrm{Si}$ ratio can effectively reduce the TD density.
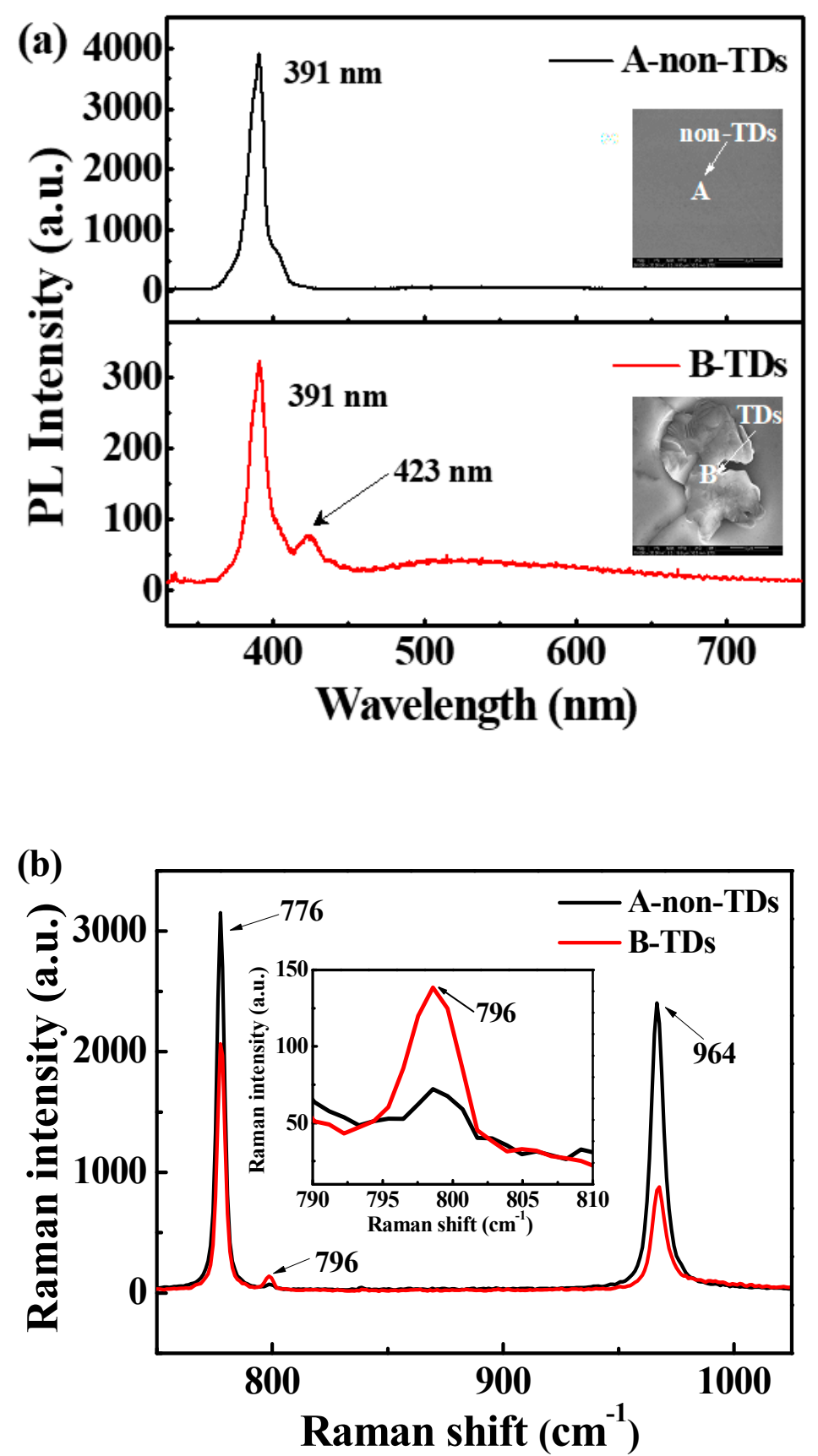

Figure 1. (a) Room temperature micro-photoluminescence (PL) spectra. The insets show scanning electron microscopy (SEM) images of region A (non-triangular defects (TDs)) and region B (TDs); (b) Micro-Raman spectra corresponding to the A and B positions in the $4 \mathrm{H}-\mathrm{SiC}$ epilayer grown with $\mathrm{C} / \mathrm{Si}=1.1$. The inset is a comparison of the intensity of the Raman peak at $796 \mathrm{~cm}^{-1}$ in the enlarged view. 


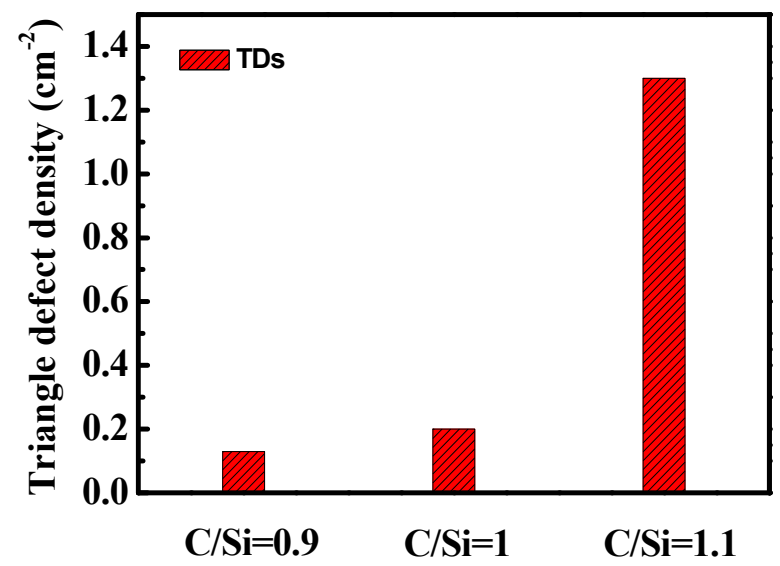

Figure 2. The C/Si ratio dependence of TDs density for $4 \mathrm{H}-\mathrm{SiC}$ epilayers (\#1 \#3).

It is well known that TDs are fatal to power devices, directly causing device failure. Moreover, although the TDs could be got rid of in most areas of the epitaxial wafer by a proper C/Si ratio, there still exist some hidden defects that affect device performance, such as interface states and deep defects, etc. Therefore, we selected the devices without TDs on the epilayer region to further investigate the effect of hidden defects on the performance of $4 \mathrm{H}-\mathrm{SiC}$ SBDs prepared on epilayers with different $\mathrm{C} / \mathrm{Si}$ ratios $(\mathrm{C} / \mathrm{Si}=0.9,1$ or 1.1$)$. Figure 3 a shows the mean values of the reverse current density varying with the $\mathrm{C} / \mathrm{Si}$ ratios under the reverse bias voltage of $-200 \mathrm{~V}$. It is noted that there is still a minor difference in device performance due to process unevenness even in the same wafer. In order to eliminate the influence of the performance non-uniformity between devices, we analyzed the average reverse $I-V$ results of five samples randomly selected on each wafer, and $\mathrm{Ni} / 4 \mathrm{H}-\mathrm{SiC}$ SBDs with $\mathrm{C} / \mathrm{Si}=1$ is shown as an example in the inset of Figure 3a. It is found that the average values of the reverse current density of Ni/4H-SiC SBDs with $\mathrm{C} / \mathrm{Si}=0.9,1$ or 1.1 are $1.8 \times 10^{-12} \mathrm{~A} / \mathrm{cm}^{2}, 5.6 \times 10^{-12} \mathrm{~A} / \mathrm{cm}^{2}$, and $1.5 \times 10^{-11}$ $\mathrm{A} / \mathrm{cm}^{2}$, respectively. With the increasing of $\mathrm{C} / \mathrm{Si}$ ratios, the reverse leakage current gradually increases. Compared with the sample with $\mathrm{C} / \mathrm{Si}=0.9$, the leakage current of the sample with $\mathrm{C} / \mathrm{Si}=1.1$ increases by nearly an order of magnitude. Figure $3 b$ shows the forward $I-V$ characteristics of Ni/4H-SiC SBDs under different $\mathrm{C} / \mathrm{Si}$ ratios. It is seen that all samples have relatively uniform and consistent forward $I-V$ curves. According to the thermionic emission (TE) theory, the relationship between current and voltage is defined by [40]

$$
J=A^{*} T^{2} \exp \left(\frac{-q \Phi_{B}}{k T}\right)\left[\exp \frac{q V}{n k T}-1\right]
$$

Here, the values of the barrier height $\Phi_{B}$ and the ideality factor $n$ can be calculated by

$$
\begin{gathered}
n=\frac{q}{k T}\left(\frac{d V}{d \ln J}\right) \\
\Phi_{B}=\frac{k T}{q} \ln \left(\frac{A^{*} T^{2}}{J_{s}}\right)
\end{gathered}
$$

where $n$ is the ideality factor, $V$ is the applied voltage, $\Phi_{B}$ is the zero bias Schottky barrier height and $A^{*}$ is the effective Richardson constant with $146 \mathrm{~A} / \mathrm{cm}^{2} \mathrm{~K}^{2}$ for $4 \mathrm{H}-\mathrm{SiC}$. The values of ideality factor $n$ and barrier height $\Phi_{B}$ obtained from $I-V$ characteristics, and the values of effective doping density $N_{\text {eff }}$ extracted from $C-V$ characteristics in the inset of Figure $3 \mathrm{~b}$ were summarized in Table 2 . The $n$ and $\Phi_{B}$ are all approximately 1 and $1.63 \mathrm{eV}$, showing good rectification characteristics. Moreover, the $N_{\text {eff }}$ are in the range of $1.15 \sim 1.25 \times 10^{15} \mathrm{~cm}^{-3}$. Therefore, the barrier height and the effective doping density are not the root cause of the increase in reverse leakage current as the C/Si ratios increases, because of the same barrier height for all samples. As is known, the leakage current of devices may be affected by a lot of factors, including surface defects, crystal defects, deep level defects, interface states, and crystal 
quality, etc. [41-43]. Combined with the above analysis, we can infer that the epitaxy process with different $\mathrm{C} / \mathrm{Si}$ ratios may affect the interface state, deep level defects or crystal quality of the epilayer, resulting in different reverse leakage current changing with $\mathrm{C} / \mathrm{Si}$ ratios.

Table 2. The electrical parameters of $4 \mathrm{H}-\mathrm{SiC}$ SBDs with different $\mathrm{C} / \mathrm{Si}$ ratios $(\mathrm{C} / \mathrm{Si}=0.9,1$ or 1.1$)$.

\begin{tabular}{cccc}
\hline Samples \# & \#1 & \#2 & \#3 \\
\hline$n$ & 1.008 & 1.004 & 1.010 \\
$\Phi_{B}(\mathrm{eV})$ & 1.629 & 1.631 & 1.629 \\
$N_{\text {eff }}\left(10^{15} \mathrm{~cm}^{-3}\right)$ & 1.25 & 1.17 & 1.15 \\
\hline
\end{tabular}
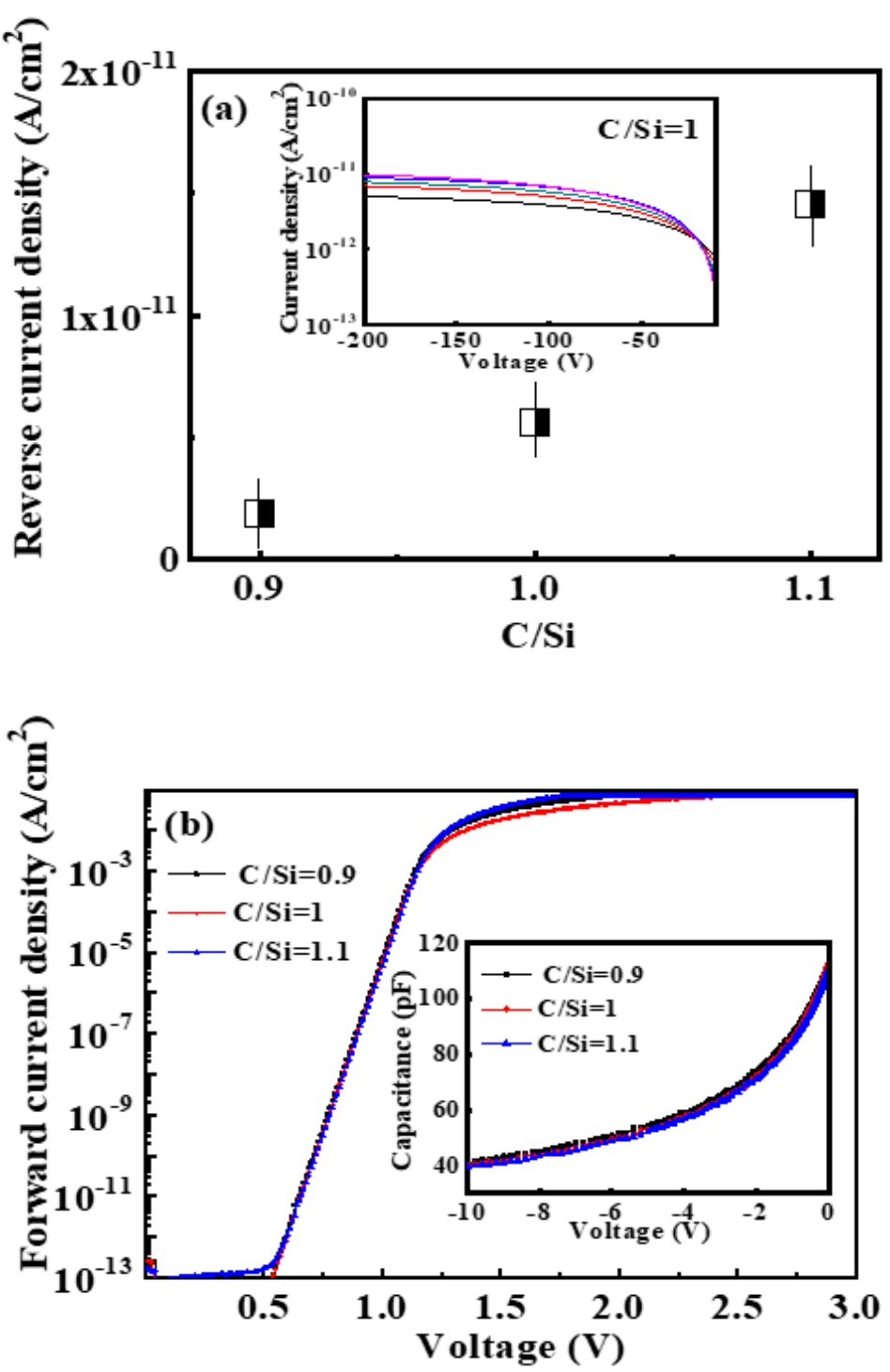

Figure 3. Cont. 

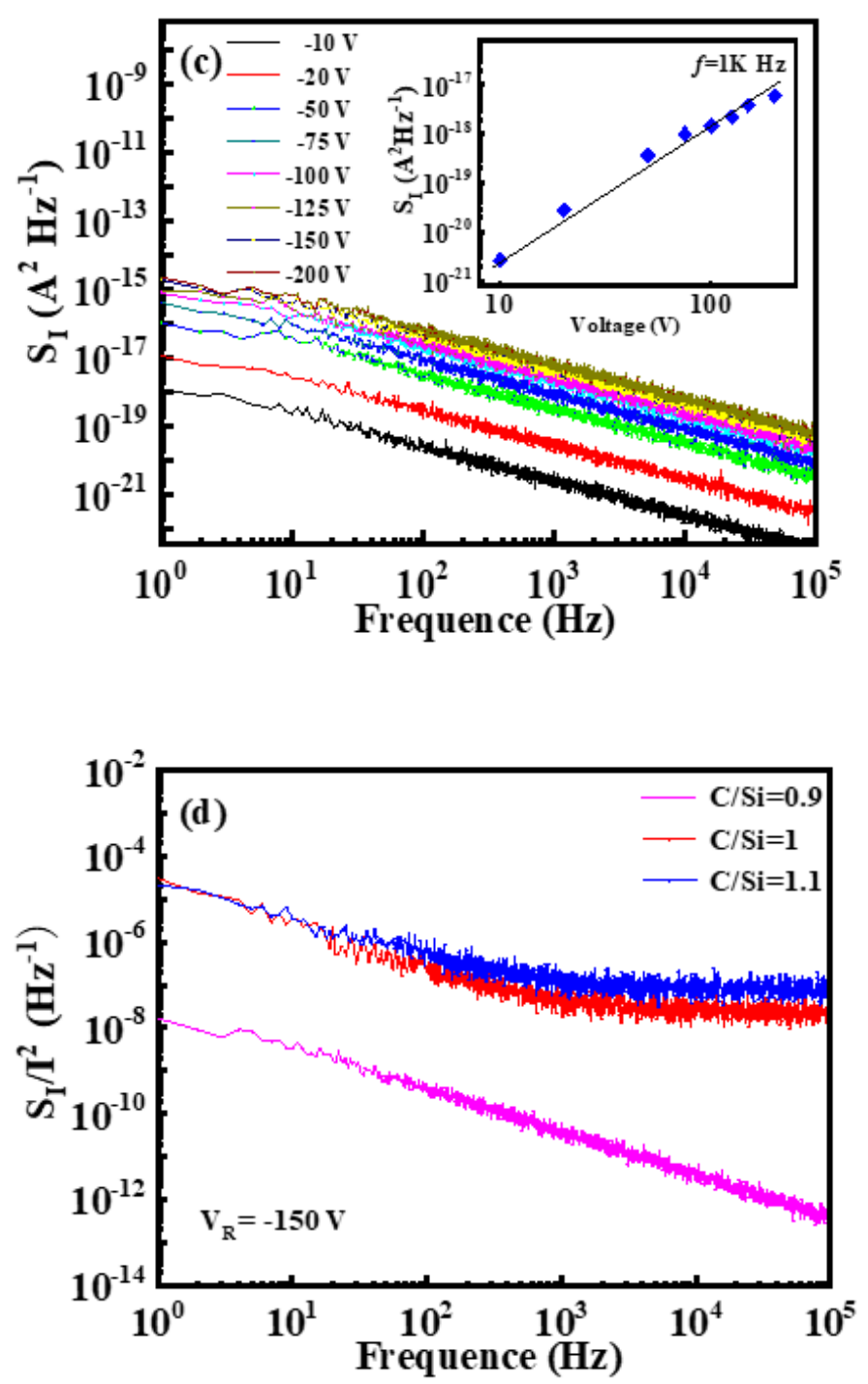

Figure 3. (a) The dependence of the mean reverse current density on $\mathrm{C} / \mathrm{Si}$ ratio for $\mathrm{Ni} / 4 \mathrm{H}-\mathrm{SiC}$ Schottky barrier diodes (SBDs) under $\mathrm{V}_{\mathrm{R}}=-200 \mathrm{~V}$. The inset shows reverse $I-V$ characteristics of a representative sample $(\mathrm{Ni} / 4 \mathrm{H}-\mathrm{SiC}$ SBDs with $\mathrm{C} / \mathrm{Si}=1)$; $(\mathbf{b})$ Forward $I-V$ characteristics of $\mathrm{Ni} / 4 \mathrm{H}-\mathrm{SiC}$ SBDs under different $\mathrm{C} / \mathrm{Si}$ ratios $(\mathrm{C} / \mathrm{Si}=0.9,1$ or 1.1$)$. The inset shows the $C-V$ characteristics of $\mathrm{Ni} / 4 \mathrm{H}-\mathrm{SiC}$ SBDs; (c) Frequency dependence of the spectral noise density $\left(\mathrm{S}_{\mathrm{I}}\right)$ for $\mathrm{Ni} / 4 \mathrm{H}-\mathrm{SiC} \mathrm{SBDs}$ with $\mathrm{C} / \mathrm{Si}=0.9$ at room temperature under $V_{R}=-10 \sim-200 \mathrm{~V}$, the inset shows the bias voltage dependence of the spectral noise density at $1 \mathrm{~K} \mathrm{~Hz}$; (d) Noise spectra of $\mathrm{Ni} / 4 \mathrm{H}-\mathrm{SiC}$ SBDs with $\mathrm{C} / \mathrm{Si}$ ratios $(\mathrm{C} / \mathrm{Si}=0.9,1$ or 1.1$)$.

Figure $3 c$ show the frequency and bias voltages dependence of the spectral noise density $\left(\mathrm{S}_{\mathrm{I}}\right)$ for the $\mathrm{Ni} / 4 \mathrm{H}-\mathrm{SiC}$ SBDs with $\mathrm{C} / \mathrm{Si}=0.9$ at room temperature under various reverse bias voltages $\left(V_{R}=-10 \sim(-200) \mathrm{V}\right)$. It is clearly observed that the spectral noise density is inversely proportional to the frequency at different voltages and increases approximately linearly with the increase of the reverse bias voltage. It has the form of $1 / f^{\alpha}$ noise, where $\alpha=1$, its characteristics is flicker noise ( $1 / f$ noise). This dependence is consistent with the reported results of SiC Schottky diodes $(\alpha=0.5 \sim 1.5)[44,45]$. The main contribution to $1 / f$ noise and resistance noise comes from the Schottky barrier. Figure $3 \mathrm{~d}$ shows the noise spectra of the $\mathrm{Ni} / 4 \mathrm{H}-\mathrm{SiC}$ SBDs with varying $\mathrm{C} / \mathrm{Si}$ ratios $(\mathrm{C} / \mathrm{Si}=0.9,1$ or 1.1$)$ under $V_{R}=-150 \mathrm{~V}$. It displays $1 / f$ behavior at frequencies below $1 \mathrm{~K} \mathrm{~Hz}$ for all samples. Furthermore, the spectral noise density increases with the increase of the C/Si ratio, and the minimum is obtained at $\mathrm{C} / \mathrm{Si}=0.9$. However, for the samples with $\mathrm{C} / \mathrm{Si}=1$ and 1.1 , the noise spectra become almost frequency independent at frequencies greater than $1 \mathrm{~K} \mathrm{~Hz}$. Several orders of magnitude increase in the noise are 
caused by superimposed thermal noise $\left(\mathrm{S}_{\mathrm{I}}=4 K_{0} T g\right)$ due to larger reverse current in samples with $\mathrm{C} / \mathrm{Si}$ $=1$ or 1.1 , which is in agreement with the results of Figure $3 a$. The $1 / f$ noise is mainly affected by the factors such as the interface state and crystal quality of the semiconductor material. Zhang et al. reported that the $1 / f$ noise is reduced significantly with the increase of temperature in the SiC MOSFET within a temperature range of $85 \sim 510 \mathrm{~K}$, which is attributed to the interface trap density decreasing with the temperature [46]. Soibel et al. also revealed that the $1 / f$ noise in the InAs/GaSb superlattice detector is related to the side leakage current caused by the surface states. The larger side leakage current is induced by the higher surface state density, leading to a significant increase in noise [47]. Accordingly, our results show that as the C/Si ratio decreases, the spectral noise density decreases by about three orders of magnitude $(\mathrm{C} / \mathrm{Si}=0.9)$. The influence of $\mathrm{C} / \mathrm{Si}$ ratios on device noise should be due to the surface state density or the interface state density caused by different crystal quality of $4 \mathrm{H}-\mathrm{SiC}$ epilayers. Therefore, an optimized C/Si ratio not only effectively improves the performance of SBDs, but should also improves the responsivity of the Schottky barrier UV photodetector due to the reduction of noise.

On the other hand, the $\mathrm{Z}_{1 / 2}$ is the most important deep level defect in the grown $\mathrm{N}$-type $4 \mathrm{H}-\mathrm{SiC}$ epilayer. The presence of deep level defects acts as charge trapping, capturing photogenerated carriers or increasing their recombination probability in the depletion region of the Schottky barrier UV photodetectors, leading to a significant reduction of responsivity [48]. Moreover, the trap or defect-assisted tunneling can result in the increase of leakage current and the reduction of carrier lifetime. To further understand the effects of deep defects on the electrical properties of the $\mathrm{Ni} / 4 \mathrm{H}-\mathrm{SiC}$ SBDs with different growth parameters, DLTS measurements were carried out in a temperature range of $80 \sim 550 \mathrm{~K}$. Figure 4 a shows the representative DLTS spectra of the $4 \mathrm{H}-\mathrm{SiC}$ SBD grown with a C/Si ratio of 0.9 , under the reverse bias $V_{R}=-3 \mathrm{~V}$, pulse voltage $V_{p}=0 \mathrm{~V}$, pulse width $t_{p}=50 \mu$ s and frequency $f=80 \sim 960 \mathrm{~Hz}$. It can be seen that the only peak appears in the DLTS spectrum, which can be attributed to $Z_{1 / 2}$ as an intrinsic defect in the $\mathrm{SiC}$ epilayer. The microstructure of $Z_{1 / 2}$ has been extensively studied, such as carbon vacancies $\left(V_{c}\right)$, silicon vacancies $\left(V_{s i}\right)$, reverse $\left(C_{s i}, S_{c}\right)$ or more likely defect complexes $\left(\mathrm{C}_{\mathrm{si}}+\mathrm{Si}_{\mathrm{c}}, \mathrm{V}_{\mathrm{c}}+\mathrm{V}_{\mathrm{si}}\right)$ [49]. Eberlein et al. have reported the $\mathrm{Z}_{1 / 2}$ is composed of the traps $Z_{1}$ and $Z_{2}$, and such centers reveal the negative- $U$ character with donor $(0 /+)$ levels located at $E_{c}-0.43(0.46) \mathrm{eV}$ and acceptor (-/0) levels situated at $E_{\mathrm{c}}-0.67(0.71) \mathrm{eV}$ [50]. The $Z_{1 / 2}$ has recently been showned to be most likely an acceptor level of $V_{c}$ [51].Besides, the variation of $Z_{1 / 2}$ defect concentration in all samples (\#1 \#7) is shown in Figure $4 \mathrm{~b}$. The parameters of defects are summarized in Table 3. The results show that with the change of $\mathrm{C} / \mathrm{Si}$ ratio $(\mathrm{C} / \mathrm{Si}=0.9 \sim 1.1)$, the $\mathrm{Z}_{1 / 2}$ defect concentration is $2.28 \times 10^{13} \mathrm{~cm}^{-3}, 3.79 \times 10^{13} \mathrm{~cm}^{-3}$, and $2.22 \times 10^{13} \mathrm{~cm}^{-3}$, respectively, indicating that the $Z_{1 / 2}$ defect concentration remains substantially unchanged. Litton et al. reported that the $Z_{1 / 2}$ concentration decreased with increasing carbon to silicon ratios of one, three and six due to the reduction of $C$ vacancies under a $C$-rich growth condition. However, as the carbon-to-silicon ratio increases, the TD density of its epitaxial wafers will increase sharply, which will directly cause the decrease of device performance. Compared to our experimental results, the $Z_{1 / 2}$ defect density does not change significantly with the change of the carbon-to-silicon ratio may be due to the small range of change of the carbon-to-silicon ratio [49]. In addition, as the doping concentration and growth rate increase, the $Z_{1 / 2}$ defect concentration ranges between $6.78 \times 10^{12} \mathrm{~cm}^{-3}$ and $1.41 \times 10^{13} \mathrm{~cm}^{-3}$. Lilja et al. reported that the $Z_{1 / 2}$ concentration does not show any obvious tendency with epitaxial growth rate, and the concentration of $Z_{1 / 2}$ in different epitaxial wafers is between $1 \times 10^{13} \mathrm{~cm}^{-3}$ and $4 \times 10^{13} \mathrm{~cm}^{-3}$ [52]. The above literature results is in agreement with our results. Therefore, the above experimental results show that the concentration of $Z_{1 / 2}$ intrinsic defect does not change significantly with the process parameters. The inset of Figure $4 \mathrm{~b}$ shows the dependence of the reverse current density (under $V_{R}=-200 \mathrm{~V}$ ) and breakdown voltage as a function of $\mathrm{Z}_{1 / 2}$ defect density for $\mathrm{Ni} / 4 \mathrm{H}-\mathrm{SiC}$ SBDs. It can be seen from the figure that the reverse current and the breakdown voltage have no obvious trend with the increase of $Z_{1 / 2}$ defect density. However, as the carbon-to-silicon ratio decreases from 1.1 to 0.9 , the reverse current gradually decreases, and the breakdown voltage slightly increases, 
which may be due to the optimization of interface quality leading to improved device performance. In addition, devices with different $\mathrm{C} / \mathrm{Si}$ ratios exhibit uniform and good rectification characteristics. (the $n$ and $\Phi_{B}$ are all approximately 1 and $1.63 \mathrm{eV}$, respectively). Therefore, the $Z_{1 / 2}$ defect is not the root cause of device performance degradation.
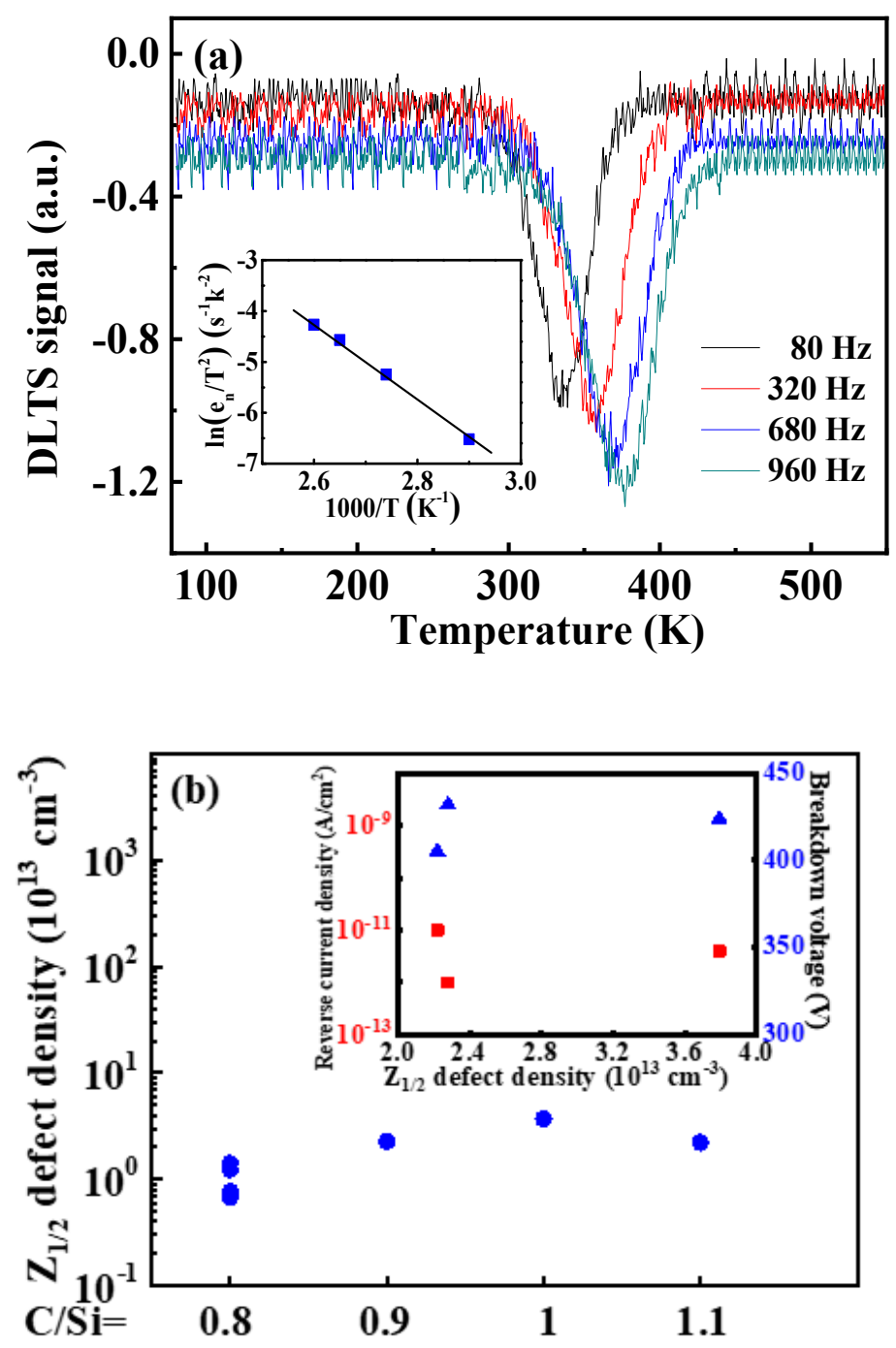

Figure 4. (a) Deep level transient spectrum testing (DLTS) spectra of Ni/4H-SiC SBD with C/Si = 0.9; (b) The $\mathrm{Z}_{1 / 2}$ defect concentration of $\mathrm{Ni} / 4 \mathrm{H}-\mathrm{SiC}$ SBDs under different $\mathrm{CVD}$ growth conditions. The inset shows the dependence of the reverse current density under $V_{R}=-200 \mathrm{~V}$ (red square symbols) and breakdown voltage (blue triangle symbols) on $\mathrm{Z}_{1 / 2}$ defect concentration for $\mathrm{Ni} / 4 \mathrm{H}-\mathrm{SiC} S B D$ s with $\mathrm{C} / \mathrm{Si}$ ratios $(\mathrm{C} / \mathrm{Si}=0.9,1$ or 1.1).

Table 3. The $\mathrm{Z}_{1 / 2}$ defect parameters obtained from the DLTS measurements of the 4 -inch $4 \mathrm{H}$-SiC epilayers with different growth parameters.

\begin{tabular}{cccc}
\hline Samples \# & $\boldsymbol{\Delta E}(\mathbf{e V})$ & $\boldsymbol{\sigma}\left(\mathbf{c m}^{\mathbf{2}}\right)$ & $\left.\mathbf{N}_{\mathbf{t}} \mathbf{( c m}^{-3}\right)$ \\
\hline$\# 1$ & $E_{\mathrm{C}}-0.627$ & $1.18 \times 10^{-15}$ & $2.28 \times 10^{13}$ \\
$\# 2$ & $\mathrm{E}_{\mathrm{c}}-0.626$ & $8.01 \times 10^{-16}$ & $3.79 \times 10^{13}$ \\
$\# 3$ & $\mathrm{E}_{\mathrm{C}}-0.624$ & $5.06 \times 10^{-16}$ & $2.22 \times 10^{13}$ \\
$\# 4$ & $\mathrm{E}_{\mathrm{c}}-0.648$ & $2.42 \times 10^{-16}$ & $7.62 \times 10^{12}$ \\
$\# 5$ & $\mathrm{E}_{\mathrm{c}}-0.644$ & $2.44 \times 10^{-15}$ & $6.78 \times 10^{12}$ \\
$\# 6$ & $\mathrm{E}_{\mathrm{c}}-0.687$ & $8.33 \times 10^{-15}$ & $1.24 \times 10^{13}$ \\
$\# 7$ & $\mathrm{E}_{\mathrm{c}}-0.610$ & $5.96 \times 10^{-16}$ & $1.41 \times 10^{13}$ \\
\hline
\end{tabular}


In order to further study the effect of C/Si ratio on the reverse leakage and noise of the device, Figure 5 a shows the AFM images of the $4 \mathrm{H}-\mathrm{SiC}$ epilayers grown with different $\mathrm{C} / \mathrm{Si}$ ratios from 1.1 to 0.9 . It is exhibited that the strong dependence of surface morphology of $4 \mathrm{H}-\mathrm{SiC}$ epilayers on the $\mathrm{C} / \mathrm{Si}$ ratios. It is observed that the surface morphology is rather smooth with gentle undulation under Si-rich growth environment $(\mathrm{C} / \mathrm{Si}=0.9)$. The root-mean-square (RMS) roughness is $0.8 \mathrm{~nm}$ at a $\mathrm{C} / \mathrm{Si}$ ratio of 1.1 , and it is decreased to $0.15 \mathrm{~nm}$ at C/Si ratio of 0.9 in a $3 \mu \mathrm{m} \times 3 \mu \mathrm{m}$ scan area. As seen in Figure $5 \mathrm{~b}$, the PL spectra of $4 \mathrm{H}-\mathrm{SiC}$ epilayers with different $\mathrm{C} / \mathrm{Si}$ ratios shows that the $4 \mathrm{H}-\mathrm{SiC}$ band edge emission intensity $(391 \mathrm{~nm})$ of the sample with $\mathrm{C} / \mathrm{Si}=1.1$ is significantly weaker than that of the sample with $\mathrm{C} / \mathrm{Si}=0.9$, which is due to the fact that the non-radiative recombination caused by the defects severely weakens the band edge emission intensity of $4 \mathrm{H}-\mathrm{SiC}$ [34]. Hence, we can see that the sample with $\mathrm{C} / \mathrm{Si}$ $=0.9$ has minimal roughness and defects, resulting in minimum noise. By comparison, in the samples of $\mathrm{C} / \mathrm{Si}=1$ or 1.1 , the quality of the wafer becomes worse, thus causing more noise.
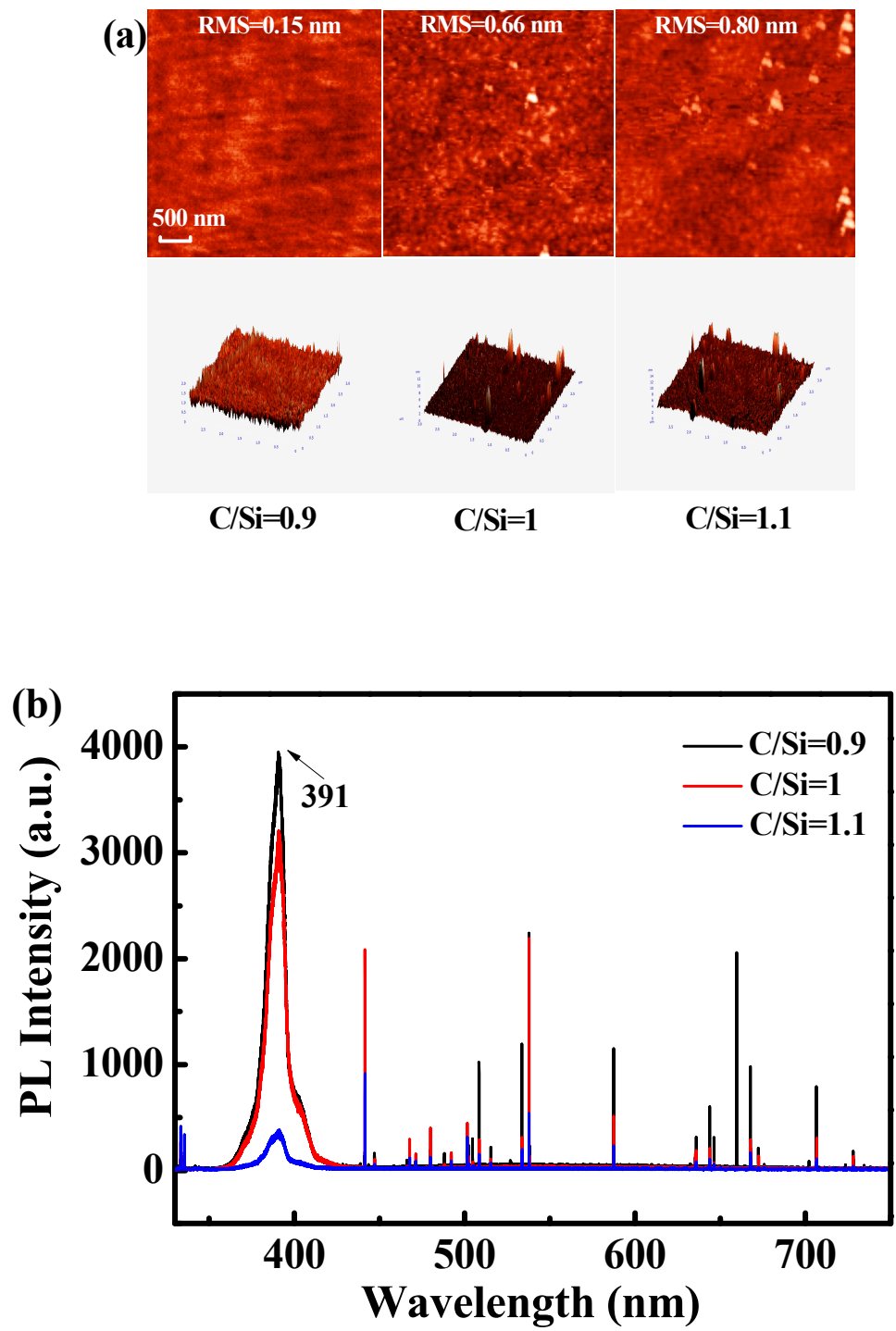

Figure 5. (a) Atomic force microscopy (AFM) images and (b) PL spectra of $4 \mathrm{H}-\mathrm{SiC}$ epilayers with C/Si ratios $(\mathrm{C} / \mathrm{Si}=0.9,1$ or 1.1$)$.

Combined with the above test result, we can see that the roughness of the epitaxial wafer and the crystal quality associated with the defects play an important role in device performance. Since the $\mathrm{Z}_{1 / 2}$ defect density and barrier height of $4 \mathrm{H}-\mathrm{SiC}$ SBDs do not change with the different CVD growth conditions, the most probable reason for the difference in reverse leakage and noise of the device 
should be the different interface state densities caused by the different epitaxial quality. Therefore, the optimization of the $\mathrm{C} / \mathrm{Si}$ ratio not only effectively reduces the TD density but also improves the performance of $4 \mathrm{H}-\mathrm{SiC} \mathrm{SBD}$.

\section{Conclusions}

The impacts of CVD growth parameters on defect density of 4-inch $4 \mathrm{H}-\mathrm{SiC}$ epilayers and performance of $\mathrm{Ni} / 4 \mathrm{H}-\mathrm{SiC}$ SBDs were studied. It is found that the reverse current and noise characteristics of $4 \mathrm{H}-\mathrm{SiC}$ SBDs are highly dependent on the $\mathrm{C} / \mathrm{Si}$ ratio. As the $\mathrm{C} / \mathrm{Si}$ ratio grows from 0.9 to 1.1 , the average reverse current and $1 / f$ noise of $4 \mathrm{H}-\mathrm{SiC}$ SBDs increase gradually. Furthermore, the DLTS characterization clarifies that the $Z_{1 / 2}$ defect is not the root cause of the device performance because the $Z_{1 / 2}$ defect density is almost unchanged with the growth conditions. The AFM and PL tests further confirm that the crystal quality of the sample becomes worse with the increase of the C/Si ratio by comparing the RMS roughness and the $\mathrm{SiC}$ band edge emission intensity $(391 \mathrm{~nm})$. Therefore, it can be concluded that the increase of leakage current and noise are due to the crystal quality of $4 \mathrm{H}-\mathrm{SiC}$ epilayers. The optimization of the $\mathrm{C} / \mathrm{Si}$ ratio can significantly reduce TD density and improve the crystal quality of $4 \mathrm{H}-\mathrm{SiC}$ epilayers, which further enhances the electrical properties of the $4 \mathrm{H}-\mathrm{SiC}$ SBDs. Moreover, the study on the influence of $\mathrm{C} / \mathrm{Si}$ ratio on $\mathrm{TDs}$ and $\mathrm{Z}_{1 / 2}$ defects should also be helpful for improving the responsivity of the $4 \mathrm{H}-\mathrm{SiC}$ Schottky barrier UV photodetectors.

Author Contributions: Conceptualization, X.J. and P.H.; data curation, X.J.; investigation, J.L.; visualization, J.L.; writing_original draft preparation, J.L.; writing_review and editing, X.J., L.Y., C.M., F.Y. and Y.L.; All authors have read and agreed to the published version of the manuscript.

Funding: This research was funded by National Key Research and Development Program of China, grant number 2016YFB0400402, 2016YFB0402403, 2016YFA0202102.

Conflicts of Interest: The authors declare no conflict of interest.

\section{References}

1. Hefner, A.R.; Singh, R.; Lai, J.S.; Berning, D.W.; Bouche, S.; Chapuy, C. SiC power diodes provide breakthrough performance for a wide range of applications. IEEE Trans. Power Electron. 2001, 16, 273-280. [CrossRef]

2. Licciardo, G.D.; Bellone, S.; Benedetto, L.D. Analytical model of the forward operation of $4 \mathrm{H}-\mathrm{SiC}$ vertical DMOSFET in the safe operating temperature range. IEEE Trans. Power Electron. 2015, 30, 5800-5809. [CrossRef]

3. Wang, X.; Cooper, J.A. High-Voltage n-Channel IGBTs on Free-Standing 4H-SiC Epilayers. IEEE Trans. Electron Devices 2010, 57, 511-515. [CrossRef]

4. Ren, N.; Wang, J.; Sheng, K. Design and Experimental Study of $4 \mathrm{H}-\mathrm{SiC}$ trenched junction barrier Schottky diodes. ISO IEEE Trans. Electron Devices 2014, 61, 2459-2465.

5. Min, S.J.; Shin, M.C.; Nguyen, N.T.; Oh, J.M.; Koo, S.M. High-performance temperature sensors based on dual 4H-SiC JBS and SBD devices. Materials 2020, 13, 445. [CrossRef]

6. Raja, P.V.; Murty, N.V.L.N. Thermally annealed gamma irradiated Ni/4H-SiC Schottky barrier diode characteristics. J. Semicond. 2019, 40, 022804. [CrossRef]

7. Zhang, X.; Ha, S.; Benamara, M.; Skowronski, M.; O’Loughlin, M.J.; Sumakeris, J.J. Cross-sectional structure of carrot defects in 4H-SiC epilayers. Appl. Phys. Lett. 2004, 85, 5209-5211. [CrossRef]

8. Konishi, K.; Yamamoto, S.; Nakata, S.; Yu, N.; Nakanishi, Y.; Tanaka, T.; Mitani, Y.; Tomita, N.; Toyoda, Y.; Yamakawa, S. Stacking fault expansion from basal plane dislocations converted into threading edge dislocations in 4H-SiC epilayers under high current stress. J. Appl. Phys. 2013, 114, 014504. [CrossRef]

9. Maximenko, S.I.; Freitas, J.A., Jr.; Myers-Ward, R.L.; Lew, K.K.; Vanmil, B.L.; Jr, C.R.E.; Gaskill, D.K.; Muzykov, P.G.; Sudarshan, T.S. Effect of threading screw and edge dislocations on transport properties of 4H-SiC homoepitaxial layers. J. Appl. Phys. 2010, 108, 013708. [CrossRef]

10. Hayashi, S.; Yamashita, T.; Miyajima, M.; Senzaki, J.; Kato, T.; Yonezawa, Y.; Kojima, K.; Okumura, H.; Miyazato, M. Structural analysis of interfacial dislocations and expanded single Shockley-type stacking faults in forward-current degradation of $4 \mathrm{H}-\mathrm{SiC}$ p-i-n diodes. Jpn. J. Appl. Phys. 2019, 58, 011005. [CrossRef] 
11. Yang, Z.M.; Lan, F.; Li, Y.; Gong, M.; Huang, M.M.; Gao, B.; Hu, J.K.; Ma, Y. The effect of the interfacial states by swift heavy ion induced atomic migration in $4 \mathrm{H}-\mathrm{SiC}$ Schottky barrier diodes. Nucl. Instrum. Methods Phys. Res. 2018, 436, 244-248. [CrossRef]

12. Lee, K.Y.; Huang, Y.H. An Investigation on barrier in homogeneities of $4 \mathrm{H}-\mathrm{SiC}$ Schottky barrier diodes induced by surface morphology and traps. IEEE Trans. Electron Devices 2012, 5, 694-699. [CrossRef]

13. Liu, L.Y.; Shen, T.L.; Liu, A.; Zhang, T.; Bai, S.; Xu, S.R.; Jin, P.; Hao, Y.; Ouyang, X.P. Performance degradation and defect characterization of $\mathrm{Ni} / 4 \mathrm{H}-\mathrm{SiC}$ Schottky diode neutron detector in high fluence rate neutron irradiation. Diam. Relat. Mater. 2018, 88, 256-261. [CrossRef]

14. Huang, L.; Gu, X. Fermi level unpinning of metal/p-type $4 \mathrm{H}-\mathrm{SiC}$ interface by combination of sacrificial oxidation and hydrogen plasma treatment. J. Appl. Phys. 2019, 125, 025301. [CrossRef]

15. Mandal, K.C.; Chaudhuri, S.K.; Nguyen, K.V.; Mannan, M.A. Correlation of deep levels with detector performance in $4 \mathrm{H}-\mathrm{SiC}$ epitaxial Schottky barrier alpha detectors. IEEE Trans. Nucl. Sci. 2014, 61, 2338-2344. [CrossRef]

16. Yamamoto, Y.; Harada, S.; Seki, K.; Horio, A.; Mitsuhashi, T.; Koike, D.; Tagawa, M.; Ujihara, T. Low-dislocation-density $4 \mathrm{H}-\mathrm{SiC}$ crystal growth utilizing dislocation conversion during solution method. Appl. Phys. Express 2014, 7, 065501. [CrossRef]

17. Yamashita, T.; Matsuhata, H.; Naijo, T.; Momose, K.; Osawa, H. Structural analysis of the 3C/4H boundaries formed on prismatic planes in 4H-SiC epitaxial films. J. Cryst. Growth 2016, 455, 172-180. [CrossRef]

18. Camarda, M.; Magna, A.L.; Via, F.L. Monte Carlo study of the early growth stages of 3C-SiC on misoriented $<11-20>$ and $<1-100>6 \mathrm{H}-\mathrm{SiC}$ substrates. Mater. Sci. Forum 2014, 778, 238-242. [CrossRef]

19. Li, Y.; Zhao, Z.; Yu, L.; Wang, Y.; Zhou, P.; Niu, Y.X.; Li, Z.H.; Chen, Y.F.; Han, P. Reduction of morphological defects in 4H-SiC epitaxial layers. J. Cryst. Growth 2019, 506, 108-113. [CrossRef]

20. Pintilie, I.; Pintilie, L.; Irmscher, K.; Thomas, B. Formation of the $\mathrm{Z}_{1 / 2}$ deep-level defects in $4 \mathrm{H}-\mathrm{SiC}$ epitaxial layers: Evidence for nitrogen participation. Appl. Phys. Lett. 2002, 81, 4841-4843. [CrossRef]

21. Guo, J.; Yang, Y.; Raghothamachar, B.; Kim, T.; Dudley, M.; Kim, J. Understanding the microstructures of triangular defects in 4H-SiC homoepitaxial. J. Cryst. Growth 2017, 480, 119-125. [CrossRef]

22. Lebedev, A.A. Deep level centers in silicon carbide: A review. Semiconductors 1999, 33, 107-130. [CrossRef]

23. Hu, J.; Xin, X.; Zhao, J.H.; Yan, F.; Kjornrattanawanich, B. Highly sensitive visible-blind extreme ultraviolet $\mathrm{Ni} / 4 \mathrm{H}-\mathrm{SiC}$ Schottky photodiodes with large detection area. Opt. Lett. 2006, 31, 1591-1593. [CrossRef]

24. Lioliou, G.; Mazzillo, M.C.; Sciuto, A.; Barnett, A.M. Electrical and ultraviolet characterization of $4 \mathrm{H}-\mathrm{SiC}$ Schottky photodiodes. Opt. Express 2015, 23, 21657. [CrossRef] [PubMed]

25. Yan, G.G.; Liu, X.F.; Shen, Z.W.; Wen, Z.X.; Chen, J.; Zhao, W.S.; Wang, L.; Zhang, F.; Zhang, X.H.; Li, X.G.; et al. Improvement of fast homoepitaxial growth and defect reduction techniques of thick $4 \mathrm{H}-\mathrm{SiC}$ epilayers. J. Cryst. Growth 2019, 505, 1-4. [CrossRef]

26. Lilja, L.; Hassan, J.U.; Booker, I.D.; Bergman, J.P.; Janzén, E. Influence of growth temperature on carrier lifetime in 4H-SiC epilayers. J. Cryst. Growth 2013, 740-742, 637-640. [CrossRef]

27. Storasta, L.; Tsuchida, H.; Miyazawa, T.; Ohshima, T. Enhanced annealing of the $\mathrm{Z}_{1 / 2}$ defect in $4 \mathrm{H}-\mathrm{SiC}$ epilayers. J. Appl. Phys. 2008, 103, 013705. [CrossRef]

28. Daigo, Y.; Ishii, S.; Kobayashi, T. Impacts of surface C/Si ratio on in-wafer uniformity and defect density of $4 \mathrm{H}-\mathrm{SiC}$ homo-epitaxial films grown by high-speed wafer rotation vertical CVD. Jpn. J. Appl. Phys. 2019, 58, SBBK06. [CrossRef]

29. Watanabe, Y.; Katsuno, T.; Ishikawa, T. Relationship between characteristics of SiC-SBD and surface defect. Hyomen Kagaku 2014, 35, 84-89. [CrossRef]

30. Fujiwara, H.; Danno, K.; Kimoto, T.; Tojo, T.; Matsunami, H. Effects of C/Si ratio in fast epitaxial growth of 4H-SIC(0001) by vertical hot-wall chemical vapor deposition. J. Appl. Phys. 2005, 281, 370-376. [CrossRef]

31. Miyazawa, T.; Tsuchida, A.H. Growth of $4 \mathrm{H}-\mathrm{SiC}$ epilayers and $\mathrm{Z}_{1 / 2}$ center elimination. Mater. Sci. Forum 2012, 717-720, 81-86. [CrossRef]

32. Yazdanfar, M.; Stenberg, P.; Booker, I.D.; Ivanov, I.G.; Kordina, O.; Pedersen, H.; Janzen, E. Process stability and morphology optimization of very thick $4 \mathrm{H}-\mathrm{SiC}$ epitaxial layers grown by chloride-based CVD. J. Cryst. Growth 2013, 113, 125-130. [CrossRef]

33. Shrivastava, A.; Muzykov, P.; Caldwell, J.D.; Sudarshan, T.S. Study of triangular defects and inverted pyramids in $4 \mathrm{H}-\mathrm{SiC} 4^{\circ}$ off-cut (0001) Si face epilayers. J. Cryst. Growth 2008, 310, 4443. [CrossRef] 
34. Feng, G.; Suda, J.; Kimoto, T. Characterization of major in-grown stacking faults in 4H-SiC epilayers. Phys. Lett. 2009, 94, 091910. [CrossRef]

35. Niwa, H.; Feng, G.; Suda, J.; Kimoto, T. Breakdown characteristics of 15-kV-class 4H-SiC PiN diodes with various junction termination structures. IEEE Trans. Electron Devices 2012, 59, 2748-2752. [CrossRef]

36. Xin, B.; Jia, R.X.; Hu, J.C.; Tsai, C.Y.; Lin, H.H.; Zhang, Y.M. A step-by-step experiment of 3C-SiC hetero-epitaxial growth on 4H-SiC by CVD. Appl. Surf. Sci. 2015, 357, 985-993. [CrossRef]

37. Chen, W.; Lee, K.; Capano, M. Growth and characterization of nitrogen-doped C-face 4H-SiC epilayers. J. Cryst. Growth 2006, 297, 265-271. [CrossRef]

38. Kojima, K.; Okumura, H.; Kuroda, S.; Arai, K. Homoepitaxial growth of 4H-SiC on -axis (0001(_)) C-face substrates by chemical vapor depositon. J. Cryst. Growth 2004, 269, 367-376. [CrossRef]

39. Leone, S.; Beyer, F.C.; Pedersen, H.; Kordina, O.; Henry, A.; Janzen, E. Growth of smooth $4 \mathrm{H}-\mathrm{SiC}$ epilayers on $4^{\circ}$ off-axis substrates with chloride-based CVD at very high growth rate. Mater. Res. Bull. 2011, 46, 1272-1275. [CrossRef]

40. Pristavu, G.; Brezeanu, G.; Badila, M.; Pascu, R.; Danila, M.; Godignon, P. A model to non-uniform Ni Schottky contact on SiC annealed at elevated temperatures. Appl. Phys. Lett. 2015, 106, 261605. [CrossRef]

41. Kyoung, S.; Jung, E.S.; Kang, T.Y.; Sung, M.Y. Optimized designing to improve electrical characteristics of $4 \mathrm{H}-\mathrm{SiC}$ wide trench junction barrier Schottky diode. Sci. Adv. Mater. 2018, 10, 416-421. [CrossRef]

42. Okino, H.; Kameshiro, N.; Konishi, K.; Shima, A.; Yamada, R. Analysis of high reverse currents of $4 \mathrm{H}-\mathrm{SiC}$ Schottky-barrier diodes. J. Appl. Phys. 2017, 122, 235704. [CrossRef]

43. Benamara, M.; Anani, M.; Akkal, B.; Benamara, Z. Ni/SiC-6H Schottky barrier diode interfacial states characterization related to temperature. J. Alloys Compd. 2014, 603, 197-201. [CrossRef]

44. Kzlovski, V.V.; Lebedev, A.A.; Levinshtein, M.E.; Rumyantsev, S.L.; Palmour, J.W. Impact of high energy electron irradiation on high voltage Ni/4H-SiC Schottky diodes. Appl. Phys. Lett. 2017, 110, 133501. [CrossRef]

45. Shabunina, E.I.; Levinshtein, M.E.; Shmidt, N.M.; Ivanov, P.A.; Palmour, J.W. 1/f noise in forward biased high voltage $4 \mathrm{H}-\mathrm{SiC}$ Schottky diodes. Solid State Electron. 2014, 96, 44-49. [CrossRef]

46. Zhang, C.X.; Zhang, E.X.; Fleetwood, D.M.; Schrimpf, R.D.; Dhar, S.; Ryu, S.H.; Shen, X.; Pantelides, S.T. Origins of low-frequency noise and interface traps in 4H-SiC MOSFETs. IEEE Electron Device Lett. 2013, 34, 117-119. [CrossRef]

47. Alexander, S.; David, Z.Y.; Ting, C.J.; Hill, M.L.; Jean, N.; Sam, A.; Keo, J.M.; Mumolo and Sarath, D.G. Gain and noise of high-performance long wavelength superlattice infrared detectors. Appl. Phys. Lett. 2010, 96, 1-3.

48. Kalinina, E.V.; Violina, G.N.; Nikitina, I.P.; Yagovkina, M.A.; Zabrodski, V.V. Proton irradiation of 4H-SiC photodetectors with Schottky barriers. Semiconductors 2019, 53, 844-849. [CrossRef]

49. Litton, C.W.; Johnstone, D.; Akarca-Biyikli, S.; Ramaiah, K.S.; Bhat, I.; Chow, T.P.; Kim, J.K.; Schubert, E.F. Effect of C/Si ratio on deep levels in epitaxial 4H-SiC. Appl. Phys. Lett. 2006, 88, 121914. [CrossRef]

50. Eberlein, T.A.G.; Jones, R.; Briddon, P.R. $Z_{1} / Z_{2}$ defects in 4 H-SiC. Phys. Rev. Lett. 2003, 90, 225502. [CrossRef]

51. Trinh, X.T.; Szasz, K.; Homos, T.; Kawahara, K.; Suda, J.; Kimoto, T.; Gali, A.; Janzén, E.; Son, N.T. Negative-U carbon vacancy in $4 \mathrm{H}-\mathrm{SiC}$ : Assessment of charge correction schemes and identification of the negative carbon vacancy at the quasicubic site. Phys. Rev. Lett. 2013, 88, 235209. [CrossRef]

52. Lilja, L.; Booker, I.D.; Hassan, J.U.; Janzen, E.; Bergman, J.P. The influence of growth conditions on carrier lifetime in 4H-SiC epilayers. J. Cryst. Growth 2013, 381, 43-50. [CrossRef]

(C) 2020 by the authors. Licensee MDPI, Basel, Switzerland. This article is an open access article distributed under the terms and conditions of the Creative Commons Attribution (CC BY) license (http://creativecommons.org/licenses/by/4.0/). 